\section{A CARTILHA MATERNAL, A CARTILHA DO POVO E A CAMINHO SUAVE: TRÊS PERSPECTIVAS SOBRE A ALFABETIZAÇÃO}

\author{
CARTILHA MATERNAL; CARTILHA DO POVO AND CAMINHO SUAVE: \\ THREE PERSPECTIVES ON LITERACY
}

Carlota Boto

Doutora em Educação

Professora da Faculdade de Educação da Universidade de São Paulo (USP) reisboto@usp.br

\begin{abstract}
Nathalia Campelo Ferraz Guirao
Graduanda em Pedagogia pela Faculdade de Educação da Universidade de São Paulo (USP) nathalia.guirao@usp.br
\end{abstract}

\begin{abstract}
Resumo
O presente artigo propõe-se a efetuar uma reflexão sobre a aplicação de alguns métodos na história da alfabetização no Brasil, a partir do estudo de três Cartilhas, consideradas exemplares em seu tempo: a Cartilha Maternal de João de Deus, datada de 1876, e seu impacto no Brasil; a Cartilha do Povo, de Lourenço Filho, que veio a público no ano de 1928; e a cartilha Caminho Suave de Branca Alves de Lima, que teve sua primeira edição datada de 1948. As três cartilhas serão tomadas como fonte documental do trabalho e serão cotejadas com a análise da bibliografia já existente sobre as mesmas. Nesse sentido, as fontes serão comparadas com a bibliografia, à luz dos procedimentos inscritos na operação historiográfica. Os resultados obtidos puderam evidenciar as modificações existentes na trajetória das práticas de alfabetização, enfocadas nas cartilhas, suas mudanças e permanências, decorrente das concepções sócio-políticas da sociedade vigente.
\end{abstract}

Palavras-chave: História da Educação; História da Alfabetização; Cartilha do Povo; Cartilha Maternal; Caminho Suave.

\begin{abstract}
This article applies to the reflection on the application of literacy methods in Brazil, elaborated by the study of three booklets, which are exemplary of the use in their time: the Maternal Booklet by João de Deus and its impact on teaching in Brazil; a Cartilha do Povo, by Lourenço Filho, which was published in 1928; and Caminho Suave by Branca Alves de Lima, that the first edition of which is dated in 1948. These three booklets must be considered as the documentary source for this work and will be collated to the analysis of the bibliography that already exists on them, in the light of the procedures inscribed in the historiographic operation. The results obtained were able to show the existing changes in the trajectory of literacy practices, focused on the booklets, their changes and permanences, resulting from the socio-political conceptions of the current society.
\end{abstract}

Keywords: History of Education; History of Literacy; Cartilha do Povo; Cartilha Maternal; Caminho Suave. 


\section{Introdução}

Doutrinar, civilizar, instruir, educar, ensinar. São termos utilizados no decorrer do processo histórico da educação brasileira, o qual tem por missão, desde a época imperial, inserir a criança no mundo da escrita e da leitura, possibilitando o acesso mais aprofundado tanto ao conhecimento quanto às relações sociais. A fim de compreender esse vínculo, o presente artigo propõe-se a refletir sobre a história da alfabetização no Brasil, por meio de três cartilhas bem-sucedidas, utilizadas como suporte ao ensino da leitura e da escrita em diferentes períodos da civilização brasileira.

Dessa maneira, busca-se analisar três cartilhas, que, sucessivamente, marcaram o período compreendido entre os anos 70 do século XIX e os anos 80 do século XX. As cartilhas sobre as quais o presente estudo se debruça são a Cartilha Maternal de João de Deus (1876); a Cartilha do Povo de Lourenço Filho (1949); e a Cartilha Caminho Suave de Branca Alves de Lima (1948). As três cartilhas são tomadas aqui como fonte documental, a serem analisadas internamente com o auxílio da bibliografia já existente sobre elas.

Neste ínterim, considerou os trabalhos realizados por Carlota Boto (2003; 2004; 2012 e 2019), compreendendo a figura de João de Deus, as lutas em prol da educação no século XIX em Portugal e suas repercussões no Brasil, por meio da Cartilha Maternal. Além de auxiliar na compreensão das mudanças e influências metodológicas nos processos do ensino da leitura e da escrita na história da alfabetização no território brasileiro.

Para análise da Cartilha do Povo de Lourenço Filho, os estudos de Estela Natalina Mantovani Bertoletti (2006 e 2011) foram essenciais para compreender as minúcias dos aspectos ideológicos e políticos presentes na criação e difusão do manual de iniciação à leitura e escrita. Afinal,

A Cartilha do povo, (...) não se caracteriza por ser um instrumento neutro com fins sim-
plistas de transmissão das técnicas do ler e do escrever, trata-se de instrumento de
divulgação e aplicação de uma mentalidade nacionalista, moralizante, que ressalta a
ideia e o sentido de nação e seus símbolos, bem como conclama a todos assumirem
suas responsabilidades como trabalhadores, estudantes, enfim, como brasileiros que
têm uma função a desempenhar para o progresso e o desenvolvimento nacional, para
ingresso do país na era da industrialização da modernidade (BERTOLETTI, 2006, p. 56)

Com o objetivo de desnaturalizar e complementar a pesquisa, as obras de Carlos Monarcha (2001 e 2010), trouxeram respaldo científico a respeito da história do grande educador e revolucionário Lourenço Filho, abarcando sob uma perspectiva mais quantitativa e estatística de seus feitos por meio da biografia. Em uma das fontes primárias analisadas por Monarcha encontrou um fragmento de Lourenço Filho escrito por ele, a qual, deixa claro seus posicionamentos sociais:

"Escola nova, para nós, é a formação do homem, sob o ponto de vista intelectual, sentimental e volitivo; é o estudo individual de cada aluno; é também, o ensino individual de cada um deles, muito embora em classes; é adaptação do programa a cada tipo de educando; é a verificação das lacunas do ensino do professor pelas sabatinas e pelos exames; é o emprego de processos especiais para a correção de deficientes mentais; é a educação física e educação profissional, caminhando, paralelamente, com o desenvolvimento mental da criança, é a preparação para a vida prática; é a transformação do ambiente escolar num perene campo de experiência social; é a escola de intensa vida cívica, de cultivo da iniciativa individual, do estudo vocacional, da difusão dos preceitos de higiene, e, principalmente, dos sentimentos da puericultura; é, em suma, a escola brasileira, no meio brasileiro, com um só láboro: formar brasileiros, orgulhosos de sua terra e de sua gente (LOURENÇO FILHO, 1918, p.1917 apud MONARCHA, 2010, p.29). 
Branca Alves de Lima também defendia a expansão do ensino, através da suavização dos conteúdos, pretendendo que seus estudantes aprendessem de uma maneira mais tranquila, sem muitas dificuldades e fardos, como é ressaltado nos estudos realizados por Eliane Peres (2015; 2016). Enquanto Jéssica Toro Perruque (2016) aborda a perspectiva cultural da cartilha nas experiências sociais durante 65 anos da história do material.

Neste âmbito, foi imprescindível obter um panorama histórico e metodológico da própria história da alfabetização e da educação brasileira, para tal, valeu-se das obras de Maria do Rosário Longo Mortatti (1999; 2006 e 2011). Maria Luiza Marcilio (2016) também contribuiu com sua ampla pesquisa, abordando diferentes pontos como: a estruturação, a materialidade e os sujeitos diretos e indiretos pertencentes ao processo educacional no Brasil de 1822 a 2014, visto que durante toda a história da alfabetização relaciona-se com o desenvolvimento do país tanto economicamente como intelectualmente, como se pode corroborar neste excerto:

"O analfabetismo constitui um dos maiores freios ao desenvolvimento de uma nação. Contribui ativamente para a marginalização da pessoa. Alfabetizar o indivíduo na idade certa é fazer dele um membro de pleno direito da coisa pública, um cidadão em sua completude" (MARCILIO, 2016, p.15)

Sob tal perspectiva, Isabel Cristina Alves da Silva Frade (2007 e 2011) proporciona uma compreensão do lugar do método na história da alfabetização com a conceituação da cultura letrada, pensando nos múltiplos campos da sociedade que impactam no processo educacional, além de conceituar os termos provenientes deste campo. Deste modo, "(...) precisamos tratar a língua como objeto de reflexão e como objeto cultural e isto, às vezes, implica em metodologias diferentes" (FRADE, 2007, p. 33).

Assim, busca-se produzir um material que auxilie a compreensão das nuances da metodologia de alfabetização brasileira, principalmente no século XX, embasada no método histórico no confronto de fontes documentais com a revisão da literatura sobre a temática, acessando em livros, artigos, revistas, teses e dissertações, como pode ser consultadas nas referências deste artigo.

\section{Breve contextualização da história da alfabetização no Brasil}

No Brasil, desde o final do século XIX, a educação ganhou destaque como uma forma de espeIhamento dos princípios sociais, como a moralidade aos bons costumes, responsabilizando a instituição escolar como promotora do preparo das novas gerações para civilidade e para o civismo, pautada sobre uma nova ordem política e social, em que as crianças deveriam ser ensinadas a ler, escrever e contar, ocasionando um processo de racionalização do cidadão, retirando-o da barbárie (BOTO, 2003 ; MARCILIO, 2016). Nesse âmbito, dá-se historicamente a defesa da expansão da escola, muitas vezes, em salas multisseriadas, abrigando alunos de todas as idades em um mesmo espaço, o que ocasionava um esforço considerável tanto dos professores, quanto de seus alunos para sua própria subsistência. Assim, o ensino carecia de uma organização e um norteamento para suas práticas educativas, principalmente quanto aos materiais usados.

Os suportes instrumentais utilizados para o ato de ensinar integram ideologias sociais e políticas com a aplicação dos métodos, a fim de atingir os seus objetivos pedagógicos e sociais. No caso dos materiais para o ensino das primeiras letras eram usados manuais, os quais se apresentaram na forma de Cartilhas, tendo por características a apresentação do alfabeto, a formação de sílabas, palavras e frases e textos religiosos, influenciados pela predominância católica advindas dos colonizadores portugueses. Pode-se, portanto, dizer o que segue: 
(...) o termo cartilha constitui um desdobramento da palavra "cartinha" que, por sua vez era usada - em língua portuguesa - desde o princípio da Idade Moderna, para identificar aqueles textos impressos cujos propósitos explícitos seria o de ensinar a ler, escrever e contar. (...) boa parte dos textos escritos que as crianças traziam de casa para utilizá-los na escola como materiais de ensino da leitura eram manuscritos: dentre esses, as cartas eram uma fonte privilegiada... Muitos eram os meninos e meninas que, em Portugal, aprenderam a ler inicialmente mediante a leitura de cartinhas... À semelhança e por analogia, elabora-se para os primeiros textos impressos com a finalidade alfabetizadora - a expressão "cartinha de leitura". Daí vem à cartilha. (BOTO, 2004, p. 333)

No âmbito da contextualização, Maria do Rosário Longo Mortatti (1999; 2006), divide a história da alfabetização brasileira em quatro períodos: $1^{\circ}$ ) A metodização do ensino da leitura; $2^{\circ}$ ) A institucionalização do método analítico; $3^{\circ}$ ) A alfabetização sob medida e $4^{\circ}$ ) Alfabetização: construtivismo e desmetodização. O último momento não será aprofundado neste texto.

Sob esta ótica cronológica, o primeiro período - no parecer de Mortatti (1999; 2006) - estende-se até os primeiros anos da Proclamação da República, aclamado como um novo mundo, instaurando novos modos e conteúdos de pensar, sentir, querer e agir. Tais fatos são concretizados com o método da palavração do português João de Deus, divulgado no Brasil por Silva Jardim, intelectual que defendia esse modelo de ensino como científico e propulsor de progresso social.

Esta perspectiva da transformação e da novidade advém da comparação com as práticas realizadas no século XIX, mediante o ensino da leitura com as chamadas "Cartas de ABC" e suas cópias frequentes, usando os métodos de marcha sintética - da soletração; da silabação e da fonética - por ordem crescente de dificuldades, partindo da parte para o todo. Segundo os estudos de Isabel Cristina Alves da Silva Frade (2007) tais métodos "(...) privilegiam a decoração de sinais gráficos e as correspondências fonográficas" (FRADE, 2007, p.22).

O segundo momento ressaltado por Mortatti (1999; 2006), denominado "A institucionalização do método analítico", acompanha uma visão republicana, difundida pelo brasileiro Arnaldo de Oliveira Barreto (MORTATTI, 1999). Cabe ressaltar que a Cartilha Maternal de João de Deus em 1876 já preconizava esse modelo de ensino. Nesse âmbito, acredita-se ser necessário retomar os estudos de Isabel Frade (2007) para compreensão dos métodos analíticos que "(...) partem do todo para as partes e procuram romper radicalmente com o princípio da decifração" (FRADE, 2007, p.26), com a justificativa de originar unidades de significado.

Contudo o método analítico começa a sofrer modificações já nas primeiras décadas do século XX, caracterizando um terceiro momento da história da alfabetização, denominado por Mortatti (1999; 2006) como "A alfabetização sob medida", juntamente com uma série de reformas educacionais, visando à regeneração nacional, em virtude da condição conturbada considerada pelos intelectuais como causa da má instrução da população, o qual impedia o progresso tão almejado nesta época (MARCILIO, 2016). Este momento promoveu reflexões acerca dos métodos e das metodologias aplicadas no Brasil, ocasionando um enfoque mais relativista.

Tal posição relativista torna-se evidente com a figura de Lourenço Filho, educador que defendia uma proposta de ensino universalizado, democrático e laico. Assim, buscou-se conciliar os vários modelos metodológicos para o ensino da leitura e da escrita, resultando no que se denominou de método misto ou eclético, o qual tinha por objetivo, contemplar todas as formas de aprendizagem, ensinando quase simultaneamente da parte para o todo e do todo para parte. 
Além disso, os impactos da psicologia no meio educativo também surtiu grande influência para a reformulação e aprimoramento dessas correntes de ensino, como por exemplo, os Testes ABC de Lourenço Filho, resultando em um ecletismo processual e conceitual mediante nivelamento embasado na maturação das crianças. Esta concepção de ensino será exemplificada pela Cartilha do Povo (1949) de Lourenço Filho.

No mesmo período também que surge a Cartilha Caminho Suave de Branca Alves de Lima, em 1948, sob influência dos testes de maturação, visto que contém 103 exercícios que introduzem e auxiliam as crianças no mundo da escrita e da leitura, embasadas no raciocínio lógico, exigindo do estudante, concentração para diferenciar e equipar as imagens. O material caracteriza-se pelo método misto, mas por meio da alfabetização pela imagem como promotor fundamental e inovador do processo de leitura e escrita pela associação entre imagens, palavras-chaves, sílabas e frases.

Diante do exposto, cabe ressaltar detalhadamente cada um dos possíveis métodos para ensinar a ler e a escrever, a fim de compreender seus princípios e defesas. Os três primeiros métodos apresentados são de caráter de marcha sintética e os dois últimos de marcha analítica.

\section{Método Alfabético ou de soletração}

O método da soletração é considerado um dos mais antigos e conhecidos pela historiografia da alfabetização brasileira. Consiste em decorar oralmente as letras do alfabeto como fundamentais para uma alfabetização, seguida do reconhecimento de todas as letras fora da ordem convencional, partindo para possíveis combinações silábicas. Os defensores desse método defendiam que a soletração ajuda o aluno a associar o nome da letra à sua representação visual e consequentemente ao som que possui na palavra, além de considerar como princípio básico de qualquer sistema alfabético como é o nosso da língua portuguesa brasileira. Entretanto, os críticos desse método ressaltam que a memorização fora do contexto afasta o estudante do significado das próprias palavras.

\section{Método silábico}

O método silábico considera a sílaba como a unidade linguística fundamental, apresentando aos alunos cantilenas como estratégias de memorização, justificando que as consoantes (unidade sem voz) só poderiam ser pronunciadas juntamente com as vogais (unidade com voz). Dessa maneira, inicia os estudos primeiro com as sílabas simples para depois ensinar as sílabas complexas. Este método foi historicamente apoiado em cartilhas, que geralmente apresentavam as famílias silábicas, podendo estar associadas a palavras-chaves ou mesmo a desenhos, inserindo gradativamente algumas frases e pequenos textos. Os defensores do método silábico ressaltam a facilidade de identificar o som, visto que, na fala, pronunciam-se sílabas e não letras, auxiliando a decifração. Contudo, os críticos de tal método condenam-no, advertindo o foco excessivo na unidade sonora e a falta de nexo entre as frases e o contexto cotidiano dos estudantes.

\section{Método fônico}

O método fônico veio a público, em língua portuguesa, com a cartilha de Castilho, em 1850, propondo a valorização sonora das letras, partindo da relação grafema-fonema, ao invés das denominações de cada letra, justificando que esta prática não auxiliava na decifração e codificação para o processo de alfabetização de cada estudante. Assim, toma como ponto de partida do aprendizado o som de cada letra, de maneira gradativa; ou seja, do som mais simples para o som mais complexo. 
Com esse método, Castilho defendia ser possível o ensino de uma leitura repentina, tendo como objetivo aprender de maneira rápida, enfocando uma alfabetização, sobretudo, auditiva. Atualmente, os autores Fernando Capovilla e Alessandra Capovilla (2007) defendem incisivamente o método fônico como a melhor maneira de ensinar os estudantes brasileiros a ler e a escrever, sendo umas das figuras-referências no documento do Plano Nacional de Alfabetização (PNA) de 2019. De acordo com tais autores, o método fônico é o oposto ao método global:

Já o método fônico afirma que o texto deve ser introduzido de modo gradual, com complexidade crescente, e à medida que a criança for adquirindo uma boa habilidade de fazer decodificação grafofonêmica fluente, ou seja, depois que ela tiver recebido instruções explícitas e sistemáticas de consciência fonológica e de correspondências entre grafemas e fonemas. (CAPOVILLA \& CAPOVILLA, 2007, p.6)

Tal disputa de métodos ou abordagens educativas já esteve presente no século XIX. Conforme o trabalho de Mortatti, nesse primeiro momento da história da alfabetização brasileira "(...) sobressai-se a disputa entre os partidários do então novo e revolucionário 'método João de Deus' para o ensino da leitura baseado na palavração e os partidários dos então tradicionais métodos sintéticos (...)" (MORTATTI, 1999, p.25), o que teria gerado embate entre o método fônico versus o método da palavração.

\section{Método da Palavração}

Com a palavração, a unidade linguística torna-se a palavra, sem que haja necessidade de divisão silábica com quebra visual da unidade gráfica. Ou seja, não se divide a palavra em sílabas, letras ou mesmo fonemas. Esse ensino consiste em apresentar diversas palavras por meio da memorização das mesmas, podendo ou não associá-las a imagens. Os defensores desse método acreditam ser a palavração uma estratégia natural do ser humano, usando a inteligibilidade do significado, trabaIhando as unidades menores sem dissociá-la do sentido do todo. Os críticos, por sua vez, apontam a possível dificuldade do aluno em reconhecer as unidades menores.

\section{Método Global ou analítico}

Abarcando o ensino, seja da palavração, seja da sentenciação, compreende-se por método global a ideia de tomar o texto como um disparador para o ensino de alfabetização, compreendendo suas sentenças, reconhecimento de expressões, palavras e sílabas, memorizando e entendendo o sentido geral do que foi "lido". Nesse método, as fases descritas acima, ocorrem quase que simultaneamente, tomando sempre como foco o sentido da escrita.

Somente após esse convívio maior com o texto é que viria uma forma de decomposição, mas com o cuidado de fragmentar o texto em parcelas maiores como primeiro a sentença e depois a palavra. Assim, se um livro constava de 10 lições, recomendava-se que só após a $4^{a}$ lição, por exemplo, é que se fizesse a fragmentação em sentenças da primeira lição aprendida. Quando se estava na $6^{a}$ lição é que se fazia a palavração da $1^{a}$ lição e assim por diante. Esse movimento mostra que havia um cuidado em não se chegar, de forma abrupta, a unidades menores e, portanto, sem sentido. (FRADE, 2007, p.27-28). 
Para tanto, busca-se no presente estudo, em alguma medida, refletir acerca do processo de alfabetização nas instituições escolares brasileiras, por meio das três cartilhas ressaltadas acima. Afinal as "(...) cartilhas são instrumentos fundamentais para a compreensão da alfabetização no Brasil, graças ao papel por elas desempenhado ao longo da história desse ensino" (BERTOLETTI, 2011, p.96), ultrapassando um caráter comercial, pedagógico ou cultural, mas marcando períodos da história, permitindo, assim, refletir e modificar a escola e suas metodologias aplicadas no processo de alfabetização. Nos próximos tópicos será contemplado as análises realizadas, descrevendo e contextualizando a Cartilha Maternal (1878), Cartilha do Povo (1949) e Cartilha Caminho Suave (1992) escolhidas como disparadoras ao pensar a história da alfabetização do Brasil.

\section{Cartilha maternal ou arte da leitura}

Os métodos simultâneos de alfabetização chegaram ao Brasil no Período Imperial, juntamente com as inovações metodológicas no ensino de ler e escrever, por meio de conhecimentos sistematizados, denominados de Cartilhas. Dentre as primeiras cartilhas, houve a Cartilha "Método português Castilho, para o Ensino Rápido e Aprazível do Ler, Escrever e Bem Falar ou Leitura Repentina" escrita por Antônio Feliciano de Castilho em 1850, a qual obteve bons resultados quanto à capacidade de atenção dos alunos, considerado na época como um grande segredo na arte de ensinar, porém 20 anos depois sofreu declínio, visto que o método levava os estudantes à práticas viciosas, sendo difíceis de extirpar, como por exemplo, a leitura cadenciada que conduzia a criança a decorar e não codificar as lições (MARCíLIO, 2016).

Apesar de seu enfraquecimento, a Cartilha de Castilho permitiu a entrada no território brasileiro de recursos educativos para além dos manuais já existentes, bem como a vinda de outros materiais portugueses com enfoque na alfabetização. A "Cartilha Maternal ou Arte de Leitura" de João de Deus - promovida pela Casa Rolland - foi um desses materiais, obtendo grandes sucesso. A obra de João de Deus foi bastante tributária da participação política de seu autor, que era um militante da famosa Geração 70, que lutava contra a mentalidade de intolerância, dogmatismo intelectual e contra a inércia retórica (MARCÍLIO, 2016). Por conta disso, a sua pedagogia tinha uma conotação ideológica e política transformando a leitura como atividade rotineira, trivial e emancipatória (BOTO, 1998), por meio do método analítico, do qual foi o precursor.

Assim, ter ciência da conjuntura sociopolítica portuguesa da década de 1870 é compreender as minúcias que justificam a criação da Cartilha Maternal, a qual foi formulada para servir de apoio pedagógico aos professores no processo de mudança ideológica e política de Portugal (BOTO, 2012).

No final do século XIX, existiu uma mudança ideológica derivada dos pensamentos republicanos advindos, principalmente dos jovens intelectuais da década de 1870, conhecidos como Geração de 70, defendendo a escolarização de forma ampla e democrática, crendo que era por meio da educação que equalizaria Portugal com os demais países desenvolvidos da Europa, ou seja, tinha como principal bandeira a reforma do ensino como meio de reformar a sociedade, levando-a uma radicalidade cultural no território português com a aquisição da leitura e senso crítico, conscientizando a população, erradicando assim, a ignorância e impulsionando para um progresso.

O nome convocado para ser o criador de um método compatível com tais ideais foi de João de Deus de Nogueira Ramos (1830 - 1896), mas conhecido como João de Deus. O referido educador compreendia que o progresso civilizatório advinha com a aquisição da leitura e escrita, principalmente da leitura, o que permitia ler os textos impressos, ampliando a visão de mundo de cada estudante, acreditando que este seria o futuro da escolarização primária. 
João de Deus não apenas criou um método que correspondesse às expectativas dos intelectuais portugueses, mas também debruçou-se sobre as necessidades da população, quanto à divisão precisa do tempo entre o trabalho agrícola e os demais afazeres. Assim, o sucesso da cartilha tanto em Portugal como no Brasil, derivou das ideias inovadoras em relação ao ensino da leitura, à nacionalização do material didático, e ao vínculo familiar, dada a aclamação que faz da família, no próprio título da Cartilha, referindo-se à figura materna com as atribuições do cuidado, da preservação da inocência, do bem querer e da proteção social.

O título da Cartilha Maternal remete-se à aproximação entre a família e o ambiente escolar, tendo como objetivo de instruir as crianças com o ensino da leitura, ou seja "(...) a palavra falada está para a família assim como a palavra escrita está para a escola" (BOTO, 2012, p.81,82), havendo, portanto, uma relação. Neste âmbito, pode-se afirmar que João de Deus acreditava que a soletração causaria danos violentos contra a amputação moral dos estudantes como corroborado neste trecho. O ponto de partida da Cartilha de João de Deus não era sequer a sílaba; era a palavra:

As mães que do coração professam a religião da adorável innocencia, e até por instincto sabem que em cérebros tão tenros e mimosos todo o cansaço e violência póde deixar vestígios indeléveis, offerecemos, neste systema profundamente prático, o meio de evitar a seus filhos o flagello da cartilha tradicional (JOÃO DE DEUS, 1878, p. VIII).

Vale destacar que o segundo título dado à obra, a 'Arte de Leitura', relacionando-se com a inovação proposta pelo autor, através do método da palavração que correspondia a ensinar partindo da palavra e seu significado, utilizando a lógica da fala, ou seja, valia-se de algo natural das características humanas para ensinar a ler, obtendo um ensino significativo, fundado na "língua viva" (JOÃO DE DEUS, 1878, p. VII), em que a leitura pretendia ser a confirmação da fala (BOTO, 2012).

Esta obra foi o primeiro manual analítico de alfabetização para os mestres brasileiros. Foi divulgado por Silva Jardim, um positivista radical que defendia o "método João de Deus" como revolucionário, científico e racional, visto que as crianças eram ensinadas a compreender e raciocinar, diferenciando do método anterior em que considerava pouco reflexivo, moldando os alunos em simples máquinas por meio da repetição (MORTATTI, 2000). Como meio da divulgação, Silva Jardim apresentou a Cartilha Maternal para os estudantes da Escola Normal de São Paulo, contendo 25 lições, indo das mais simples às mais complexas. Tal Cartilha foi bem aceita por toda categoria docente, visto as inúmeras edições publicadas, que foram inclusive distribuídas nas escolas brasileiras pelas autoridades do país (MARCÍLIO, 2016).

Foi com o professor Júlio Francisco da Silva Mirando que o método começou a ser ensaiado nas escolas primárias brasileiras, especificamente no Estado de Recife no ano de 1880. Em sua experiência, o professor afirmava ser um dos melhores métodos já aplicados, embora fossem necessárias salas espaçosas que possibilitassem espalhar cartazes nas paredes, facilitando a aula. Já o professor Antônio Hipólito de Medeiros, vangloria o "método de João de Deus", dizendo que, mesmo com as condições da instrução pública sendo péssimas, o método era uns dos melhores já ensinados, visto que seus alunos aprendiam a ler e escrever bem rápido, aproximadamente em três meses já possuíam uma leitura fluida (MARCÍLIO, 2016).

Neste âmbito, é relevante compreender como era a estruturação do material considerado tão revolucionário. De acordo com estudos de Isabel Ruivo (2006), a letra de imprensa usada em toda a extensão da obra e as ferramentas de destaque como o negrito e/ou a cor cinza para distinguir algumas sílabas, utilizadas como uma diversificação da divisão silábica das palavras, auxiliavam na compreensão do aluno, sem que houvesse quebra da unidade gráfica e sonora. Assim o estudante aprendia os valores das letras e palavras inteligíveis, mostrando a arte do ler e não do gaguejar (OLIVEIRA, 1998). 
Outro ponto chave é a abordagem das letras de acordo com seu valor sonoro, agrupando fonemas similares, sempre em busca de ensinar com sentido e rapidez a leitura.

João de Deus qualifica o valor de cada letra, dando-lhe a entonação da leitura, a partir do modo pelo qual ela deveria ser pronunciada. Tal preocupação fica exposta na sequência de seu texto, quando classifica a fala em função não mais do critério binário das vogais e consoantes, mas pelo parâmetro quaternário que supunha vozes (as vogais puras e nasaladas), tons $(v, z, j . r)$, sons $(f, c, x)$ e modos [labiais $(m, b, p)$ e linguais; divididos, por sua vez, em dentais (d, t), palatais ( $r$, I, Ih) e guturais $(\mathrm{g}, \mathrm{q})$ ] (BOTO, 2012, p.83).

Dessa maneira, as lições são divididas de acordo com os modos de articulação da fala, ao invés da utilização da sequência alfabética, utilizando o método analítico focando no método da palavração, partindo da palavra mais fácil para a mais difícil, da simples para a composta como ressalta Mortatti (2000):

Como aprendemos a falar? Falando palavras; como aprenderemos a ler? É claro que lendo essas mesmas palavras. A palavração, pois, é o único processo nacional; porque não ensina o alfabeto todo e sim por partes; porque não arbitrariamente e sim partindo das vogaes, sons elementares e geraes, comuns, para as invogaes, sons secundários e espaciaes, (...), porque finalmente torna explícito que para ler não são necessários nomes de letras e sim seus valores, por isso que só estes são falados (...) (MORTATTI, 2000, p.48).

Embora João de Deus tenha iniciado sua Cartilha apresentando as vogais, isso não caracteriza seu método como sintético, visto que o autor compreende as vogais como vozes, mas usava-as pelo significado extraído da junção de mais de uma vogal (ai; ui; eu; ia), ou seja, "o princípio para João de Deus, deveria ser sempre a inteligibilidade da palavra" (BOTO, 2012, p.81), posto que se compreendia a leitura como a própria soletração, justificando que a leitura atribui caráter de justo valor (JOÃO DE DEUS, 1878, p.29).

Dessa forma, João de Deus não utiliza o método fonético (sons), sendo usado o processo de leitura pela palavra inteira, aplicando seu conceito de ensinar os estudantes a ler pela mesma lógica da fala, partindo sempre do significado da própria palavra. Diante do exposto, cabe exemplificar e analisar uma das vinte e cinco lições contidas na Cartilha, ressaltando que todas utilizam tonalidades diferentes da cor cinza para destacar as sílabas das palavras. Ou seja, o autor usa cores próximas ao preto para enfatizar a sílaba trabalhada na lição, deixando as demais letras coloridas de cinza claro, a fim de facilitar a compreensão do discípulo. Esta prática é utilizada da segunda lição à vigésima quarta. Outra característica da cartilha é o termo invogal, atribuído às consoantes, usando o prefixo "in" como negação ao significado da palavra vogal (com voz). João de Deus reporta-se a invogais certas $(b-d-f-j-k-l-p-q-t-v)$ e invogais incertas $(c-g-m-n-r-s-x-z)$, justificando tal agrupamento pelas irregularidades fonêmicas. Também é importante ressaltar que o autor tem costume de realizar algumas revisões utilizando palavras já estudadas. Sendo assim, o autor segue uma sequência na apresentação e rememoração do estudante, a fim de compreender o som e o valor de cada invogal ensinada. Sob tal perspectiva, o autor utiliza nas últimas lições o uso de neologismos para facilitar a aprendizagem do aluno, como por exemplo na vigésima terceira lição que ensina a letra "N": - Que letra é essa? / - Netil / - Que vale? / - Língua no ceo da boca (n'); e é signal de voz nasalada. / - Quando é signal de voz nasalada? / - Quando não tem vogal adiante" (DEUS, 1878, p.93). 
A Cartilha Maternal, por se propor a ensinar o professor, possui trechos nos quais João de Deus explica suas perspectivas políticas e educacionais. Na primeira lição consta que a educação deveria ser expandida para a população, pois apenas a instrução deixaria o homem livre da selvageria, sendo por meio da escrita que se consolida a palavra do homem, pois é imortal (JOÃO DE DEUS, 1878). Tais ideias também são ressaltadas nos poucos e pequenos diálogos utilizados como exercícios de leitura a partir da décima sexta lição. Foi escolhida a sétima lição como meio de elucidar a ideia do leitor, visando uma possível comparação entre as demais cartilhas a serem ponderadas. A lição sete inicia-se criticando a regra de acentuação e seu mau uso, até mesmo pelos escritores reconhecidos. João de Deus explica o motivo de ter acentuado a palavra "dúvida" na lição anterior, tendo por objetivo facilitar a leitura do estudante.

Queremos dizer com isto, que rejeitando e reprovando nas cartilhas uma acentuação artificial armada a facilitar a leitura, iremos empregando os devidos signaes nas palavras duvidosas, conforme a razão e os bons exemplos (DEUS, 1878, p.19).

Na sequência, a Cartilha apresenta a invogal 'bê', ensinando o modo de articulação, em que se lê com a boca fechada, assim como será trabalhada a letra "P" (pê), dando sequência a próxima lição. Ensinam-se 17 palavras que contenham a invogal 'bê', sendo 10 iniciadas por esta consoante e as demais pela vogal "A". É perceptível que as palavras não possuem relação semântica, embora haja uma correspondência sonora, até mesmo ritmada, ao ler rapidamente todas juntas. São utilizadas palavras matrizes, adicionando prefixos e sufixos, como é possível ver na tabela abaixo:

Tabela 1. Lição 7 (Cartilha Maternal)

\begin{tabular}{|c|c|c|c|c|}
\hline \multicolumn{2}{|c|}{ SÉTIMA LIÇÃO } & \multicolumn{3}{c|}{ LETRA B } \\
\hline Boi & boa & aba & baba & beba \\
\hline Bata & batia & bateu & batida & bota \\
\hline Batata & abata & abatia & abatida & abafa \\
\hline Abafava & abafada & & & \\
\hline
\end{tabular}

Imagem 1: Lição sete - o estudo da letra "bê"
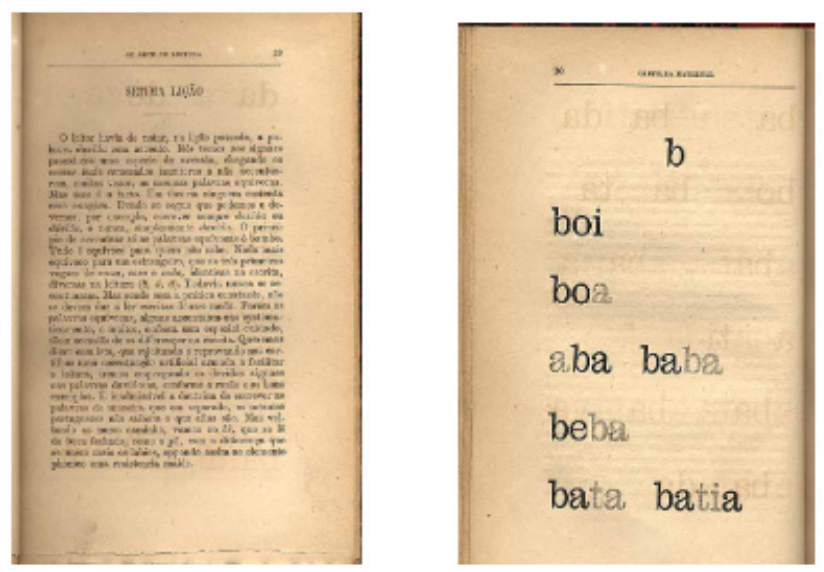

Fonte: CARTILHA MATERNAL, 1878, p.21

Nas imagens acima, é possível notar a estruturação do método analítico promovido pelo autor, já detalhado anteriormente, concretizando-o e justificando o sucesso de vendas, advindo principalmente da aceitação social vinculado à figura materna relacionada ao cuidado, além do pensamento colonizador, o qual, em princípio, retiraria as pessoas da barbárie, civilizando-as por meio da alfabetização. 
Dessa forma, consta que a figura de João de Deus e sua obra, Cartilha Maternal, foram de extrema importância para o desenvolvimento da educação brasileira, contendo o método analítico, ensinando os alunos a compreender e raciocinar, através da diferente formas de abordagem das letras, de acordo com seu valor por meio das cores preta e cinza. A cartilha de João de Deus foi usada até os primeiros anos da República do Brasil, quando surge a necessidade de haver materiais criados pela própria nação, advindos do sentimento nacionalista e progressista da época. Hoje, o autor ainda permanece relembrado em Portugal, sendo homenageado no Museu de João de Deus, situado na cidade de Lisboa, além da Associação de Jardins-Escolas João de Deus que tem por objetivo promover a educação e a cultura nas crianças pequenas.

\section{Cartilha do povo}

A preocupação em expandir a educação para uma maior parcela da população tornou-se mais marcante após a Proclamação da República em 1889, a qual, enfatiza um sentimento nacionalista, reverberando nas instituições escolares, visto à importância de haver crianças bem educadas, as quais só seriam suscetíveis por meio de um processo escolar civilizatório (BOTO, 2012 ; MARCÍLIO, 2016).

No período republicano houve importantes reformas educacionais, visando à regeneração nacional, em virtude da condição conturbada considerada pelos intelectuais como causa da má instrução da população, a qual impedia o progresso tão almejado, atingindo desde a educação básica até a educação profissionalizante.

Manoel Bergström Lourenço Filho cria a Cartilha do Povo - Para ensinar a ler rapidamente, em 1928, publicada pela editora Companhia Melhoramentos de São Paulo. A referida cartilha era destinada ao ensino da alfabetização para crianças e adultos brasileiros, contendo todos os preceitos morais, éticos e sociais da luta dos intelectuais republicanos.

Lourenço Filho foi um dos expoentes da Geração de 1920, a qual apregoou a educação a todos em prol ao progresso da nação, conscientizando o povo por meio da escola pública, considerada o motor da sociedade. Ou seja, a Geração de 1920 contemplava intelectuais operantes da construção de uma cultura brasileira, valorizando-a, sendo assim "(...) uma geração construtora, sumamente empenhada na invenção de outro sistema de expressão de vida para, assim, superar os impasses próprios de uma formação social saturada de tensões e conflitos" (MONARCHA, 2010, p.14).

Também foi grande estudioso das mais novas metodologias de ensino, e o fez a partir de sua experiência em todas as etapas da educação, desde o pré-primário até o Ensino Superior, vivendo durante toda sua vida em prol da Educação e acreditando que é por meio dela que a nação progride. De fato, Lourenço Filho é um dos nomes mais citados nas reformas educacionais dos anos 20 e na batalha em prol ao desenvolvimento do país por meio das instituições escolares, sendo de grande admiração por diversos educadores e pessoas anônimas tanto de sua época, como atualmente, transpassando seus ideais. Defendia as bandeiras de lutas de sua geração: educação pública, gratuita e laica; garantir igualdade entre os sexos e remuneração digna para os professores, assim como a formação dos mesmos. Lourenço Filho concretizou seu pensamento com inúmeras publicações durante toda sua vida, chegando a mais de 771 obras, recebendo mais de 21 prêmios, 19 títulos, 23 cargos, 12 convocações para representar o Brasil, além das 369 referências bibliográficas comentadas e interpretadas por diversos autores, os quais foram influenciados por ele e as 9 Instituições Educacionais que atualmente levam seu nome (MONARCHA, 2001). 
A Cartilha do Povo - Para ensinar a ler rapidamente, é “(...) um pequeno livro de 48 páginas, com quarenta lições, que, decorridos mais de 60 anos, já alcançou mais de 2.200 edições, com mais de 25 milhões de exemplares (...)" (MONARCHA, 2001, p. 32). Essa cartilha obteve muito sucesso desde a sua primeira edição que obteve 1.080 .000 exemplares, dando continuidade a números superiores nas edições seguintes, somando mais de 2 milhões de exemplares nas primeiras décadas de sua criação, expandido esse número até a última edição encontrada, datada de 1986 (Documentário TV ESCOLA, 2011; BERTOLETTI, 2006). A Cartilha do povo teve, pois, uma grande popularidade e intensidade maior na década de 1950, decaindo seus números só após 1980. Essa popularidade decorria de dois pontos principais: o sentimento nacionalista de obter materiais brasileiros, pensados e produzidos para esta nação e a abrangência que o educador procurou promover em todos os níveis de ensino, contemplando e incentivando a Educação de Jovens e Adultos. Assim sendo, a Cartilha tinha por objetivo atingir a Educação Popular, ensinando "o civismo, a capacidade de produção, a saúde, o emprego sadio das horas de lazer". (LOURENÇO FILHO, 1953, p.2 apud MORTATTI, 2000, p.172173). Cabe destacar que tal amplitude também decorreu pela venda dos direitos autorais de Lourenço Filho para a Companhia Melhoramentos, a qual, desde o primeiro exemplar, realizou a publicação do texto, procurando contribuir para a ampliação do material, a fim de atingir o maior número de analfabetos brasileiros (BERTOLETTI, 2006).

A Cartilha do Povo, feita para o povo, utilizava o método misto intercalando o método sintético com o método analítico, em virtude da posição relativista assumida por Lourenço Filho em relação aos métodos de alfabetização. Lourenço Filho recorre à Psicologia e ao conceito de maturação biofisiológica, estudado pelos psicólogos Jean Piaget e Vygotsky, defendendo que há um nível de maturação do desenvolvimento da criança para a aprendizagem simultânea da leitura e da escrita, pois, de acordo com essa vertente, ambas as atividades se relacionam com condutas do pensamento do aluno, resultando em uma aprendizagem mais rápida. A obra possui lições que podem tanto ser ensinada pelo método sintético, como o método analítico, ou mesmo mesclando-os, como ressalta o autor:

As lições tanto podem servir ao ensino pela silabação como pela palavração. Neste caso, o aprendizado deve ser iniciado na $4^{a}$ lição. Recomenda-se a quem se encarregue do ensino, professor ou leigo, que desde logo leve os alunos a escrever, no quadro negro ou no caderno, mediante cópia de modelos que para isso prepare, e depois, sob ditado. A escrita deve ser feita em letra manuscrita, sem que as sílabas se apresentem separadas, como aparecem nas primeiras lições do livro. Desde o início, se o ensino estiver sendo feito pela silabação, ou, quando julgado conveniente, se estiver sendo feito pela palavração aconselha-se que os alunos organizem uma coleção de pequenos cartões ou pedacinhos de papel, em que eles próprios escrevem as sílabas aprendidas. Com esse material, tão fácil de obter-se, terão as crianças elementos de um jogo que lhes despertará grande interesse, e que servirá tanto aos exercícios de verificação das palavras e sílabas aprendidas como aos de invenção para descoberta de novas palavras ou combinações destas em sentenças. $\mathrm{O}$ aluno mais rapidamente compreenderá às historietas apresentadas nas últimas páginas, umas originais, outras adaptadas (LOURENÇO FILHO, 1953, p.2 apud MORTATTI, 2000, p.172).

É relevante esmiuçar a Cartilha física, ponderando que a análise foi realizada na edição $586^{a}$ de 1949. A obra apresenta 40 lições dividindo-as por página, isto é, cada lição é transcrita em uma página, mesmo que seja continuidade do conteúdo anterior. O ensino é iniciado com as vogais, seguidas de suas combinações em ditongo com as consoantes b, l, n, c, t, d, m, v, etc., em uma progressão que se tornou clássica, ou seja, consoantes labiais, dentais e nasaladas, partindo das constituições silábicas mais simples para as mais complexas, separando-as por hífen (BERTOLETTI, 2006) 
A maioria das lições são grafadas em letra de imprensa, de tamanho uniforme e os conteúdos apresentados de maneira sistematizada e gradual. A cada novo conteúdo ensinado, há aparições nas lições seguintes como reforço, entretanto cabe ao "(...) professor sistematizá-lo ou não, uma vez que a Cartilha é apresentada apenas como instrumento de leitura inicial (BERTOLETTI, 2006, p.31). Pode-se compreender a estrutura da obra com base nos de Estella Bertoletti (2006), abaixo mencionada:

(....) A Cartilha se inicia com a apresentação das cinco vogais, imediatamente seguidas de sua combinação em ditongos. A partir da $3^{a}$ lição, passam a ser introduzidas as consoantes, não em ordem alfabética, mas de acordo com uma "coordenação que tornasse possível o maior número de combinações representativas de palavras do vocábulo natural das crianças: b, I, n, v, c, etc. Até a $11^{a}$ lição, repete-se a mesma sequência: ilustração, vocábulo correspondente em tipo grande e com negrito, destaque das sílabas, novos vocábulos formados por diferentes combinações dessas sílabas e, por fim, frases numeradas formadas com os vocábulos aprendidos até então, apresentando-se, em todas as situações, as palavras divididas em sílabas com um hífen. Da $11^{a}$ a $24^{a}$ edição, mantêm-se os aspectos apontados, mas frases e palavras. A partir da $25^{a}$ lição, acrescentam-se as sílabas complexas, e as palavras das frases são apresentadas sem o hífen para divisão das sílabas. Da $35^{a}$ à $36^{a}$ lição, é apresentado o alfabeto, em letras maiúsculas e minúsculas, de imprensa e manuscrita, são destacados os dígrafos e reapresentados vocábulos que se iniciam com as letras do alfabeto e sempre divididos em sílabas. As quatro últimas lições apresentam historietas, com frases numeradas, duas delas com uma frase manuscrita à guisa de "moral da história", e as duas lições finais versam sobre temas cívico- nacionalistas: "A nossa bandeira" e "Minha terra". Encerrando a Cartilha, encontra-se, em tipo pequeno, a letra do Hino Nacional Brasileiro (BERTOLLETI, 2006, p.173-174).

Há de se destacar a diferenciação da Cartilha do Povo e da Cartilha Maternal, principalmente quanto às ilustrações, vistas como algo novo para a época. Na Cartilha do Povo, há, ao todo, 125 ilustrações, remetendo à infância, objetos domésticos e figuras humanas, todas de pele branca, além de todos os desenhos possuírem traços próximos ao real, trazendo uma preocupação a não infantilização do adulto. (BERTOLETTI, 2006).

Foi escolhida a lição de número três que retrata a letra "B" como norteadora do trabalho. A palavra-chave dessa lição é "bo-la", apresentando a família do "B" e do "L" em sentido vertical, em seguida mostra palavras constituídas por estas conjunções e expõe a família silábica de ambas as letras, em sentido horizontal. Por fim, ensina três frases simples, relacionando as palavras já aprendidas, sendo duas com o sujeito na primeira pessoa do singular e uma oração na terceira pessoa do singular.

Tabela 2. Lição 3 (Cartilha do Povo)

\begin{tabular}{|c|c|c|c|c|}
\hline \multicolumn{3}{|c|}{ TERCEIRA LIÇÃO } & \multicolumn{2}{|c|}{ FAMÍLIA DO B e L } \\
\hline \multicolumn{5}{|c|}{ PALAVRA-CHAVE: BO-LA } \\
\hline $\mathrm{Ba}$ & $\mathrm{Be}$ & $\mathrm{Bi}$ & Bo & $\mathrm{Bu}$ \\
\hline $\mathrm{La}$ & Le & $\mathrm{Li}$ & Lo & Lu \\
\hline \multicolumn{5}{|c|}{ PALAVRAS } \\
\hline ba-ba & be-be & bo-bo & boi & ba-la \\
\hline bo-lo & bai-le & bu-le & bu-li & bu-lia \\
\hline \multicolumn{5}{|l|}{ be-bê } \\
\hline \multicolumn{5}{|c|}{ FRASES } \\
\hline \multicolumn{5}{|c|}{ 1. Eu be- bi } \\
\hline \multicolumn{5}{|c|}{ 2. O bo-bo be-beu } \\
\hline \multicolumn{5}{|c|}{ 3. Eu ia ao bai-le } \\
\hline
\end{tabular}


Quanto às imagens há um número mais elevado, contando com um menino com uma bola; uma menina com outra bola; ao fundo uma outra menina; a figura de uma bola ao lado da palavra "bo-la"; a cabeça de um boi; uma figura redonda não identificada, similar com uma moeda; um bule acima da palavra "bu-le" e um bebê nu sentado em cima da palavra "be-bê".

Imagem 2. Terceira Lição

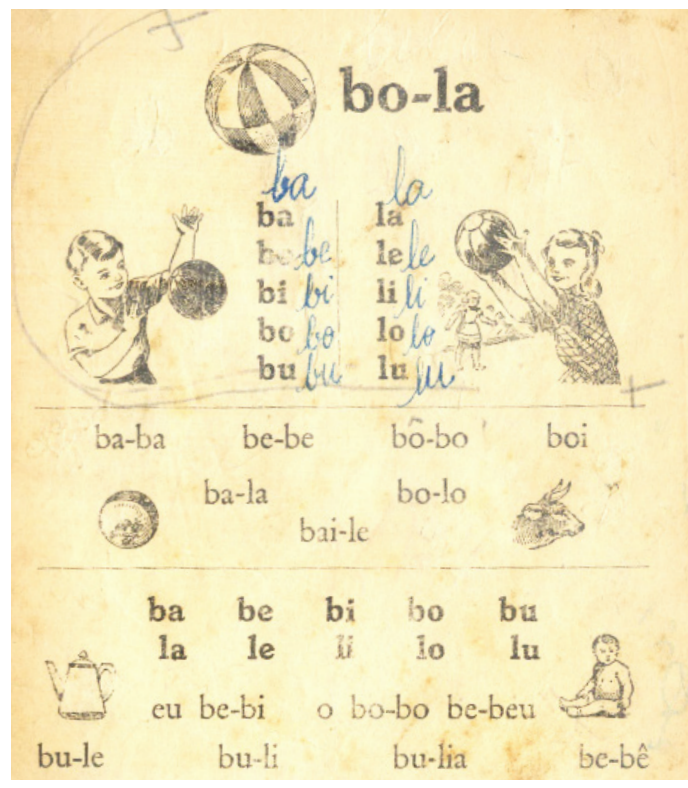

Fonte: Cartilha do Povo, 1949, p.5

Os textos são apresentados apenas nas lições finais da Cartilha, dispondo de um caráter maniqueísta, entre o bem ou o mal, além de serem moralizantes, construindo um estudante ciente das concepções do bom cidadão: trabalhador, nacionalista, etc. Indubitavelmente "Lourenço realmente foi um agente fundamental na democratização desse país" (BEISIEGEL, 2011 apud Documentário TV ESCOLA, 2011). Contudo, sua a maior preocupação, a de oferecer um instrumento auxiliador para erradicação do analfabetismo, não teve seu objetivo alcançado, embora sua cartilha e seu método inovador tenham acompanhado o aumento progressivo das taxas de alfabetização de todo território brasileiro por mais de 50 anos.

\section{Cartilha caminho suave}

Uma das pessoas influenciadas por Lourenço Filho, principalmente no que diz respeito à ideia de maturação biofisiológica, foi a autora da Cartilha Caminho Suave, Branca Alves de Lima (1911- 2001), que trazia em sua própria obra 103 atividades que introduziam e auxiliavam as crianças no mundo da escrita e da leitura, embasadas no raciocínio lógico e no desenvolvimento da motricidade fina, exigindo do estudante, concentração para diferenciar e equipar as imagens, considerando-as como imprescindíveis para compreender as lições posteriores.

Além dos Testes $A B C$ de Lourenço Filho, Branca foi influenciada pela sua própria experiência, trabalhando mais de 15 anos consecutivos na primeira série do antigo ensino primário, com extraordinários resultados (MARCÍLIO, 2016). Contudo, em reportagens realizadas pela Folha de São Paulo, Lima relata que observou a dificuldade que alguns alunos tinham para aprender pelo método global e, em virtude desse fato, resolveu "suavizar" o ensino com um método que ela denominou "Alfabetização pela Imagem". 
A Caminho Suave surgiu a partir das experiências de Branca, uma colecionadora de cartilhas, com alunos do interior do Estado, zona rural e periferia de São Paulo. Ela diz que as crianças apresentavam dificuldades de alfabetização com o método global, usado na época, em que o aprendizado era feito a partir de frases, das quais eram destacadas palavras e por fim sílabas e letras. Partindo de sua atuação em sala de aula, Branca criou o chamado "método eclético", onde a alfabetização é feita através da associação de imagens a palavras-chave, sílaba e letras. A ideia de associar o "g" ao rabo do gato e "I" ao cabinho da laranja surgiu em cartazes feitos à mão pela autora junto com alunos (Após 40 anos..., 1990, p.C-6 apud PERES et. al., 2016, p. 345-346).

Apesar de saber que Lima não criou o método eclético, não se deve negar que a utilização da didática imagética foi inovadora, realizando o processo de alfabetização pela associação entre imagens, palavras-chave, sílabas e frases (PERUQUE, 2016). A primeira publicação deste material foi em 1948, tendo por objetivo extinguir o analfabetismo brasileiro.

Este sonho era tão presente em Branca que a primeira edição, com somente cinco mil exemplares da Cartilha, foi custeada pela própria autora com ajuda de seu pai, abrindo uma empresa de edição de livros didáticos, a qual seria conhecida futuramente como Editora Caminho Suave Limitada (PERES, et. al., 2016).

O sucesso da obra de Branca Alves de Lima foi estrondoso, sobretudo entre as décadas de 1960 a 1980, tanto por sua frequente participação em programas federais como vendas externas de escolas que adotavam o livro. O êxito da Cartilha Caminho Suave vinculada aos programas assistenciais de educação do Governo Federal com exorbitantes tiragens da Cartilha, chegou a mais de 19 milhões de exemplares editados durante 25 anos, iniciando um declínio a partir de 1995, quando o movimento construtivista influencia as práticas docentes de todo Brasil, inclusive as decisões do MEC, encerrando o contrato com a Editora Caminho Suave e inflamando diversos questionamentos dos métodos de alfabetização até então existentes (PERES, et.al., 2016). Contudo, a popularidade da cartilha Caminho Suave perdura até os dias atuais com a venda de exemplares pela Editora Edipro ou por pessoas físicas vendendo edições antigas pelas redes digitais: "(...) alguns adultos guardam tanto carinho pela obra que se rendem a certas extravagâncias. Na internet, é fácil encontrar edições muito antigas da cartilha à venda por altos valores. Para se ter ideia, há exemplares das primeiras edições que custam de $R$ \$ 250 a R\$ 440". (PERUQUE,2016, s/p.)

É evidente que tal sucesso derivou de muita dedicação de Lima, trabalhando com a Cartilha Caminho Suave por mais de 45 anos, sendo professora, editora e divulgadora do método "Alfabetização pela Imagem", ampliando seu material até a quarta série do Ensino Fundamental para alunos, além de orientações para professores, vinculados tanto dentro da Cartilha (nas edições mais antigas) como de forma autônoma, conforme se pode analisar no folheto encontrado nos estudos de Mortatti (2000):

\section{Aos professôres}

O ensino da leitura, como simples exercício monótono, não desenvolve a energia intelectual da criança, que então se limitará a acompanhar passivamente a professôra, sem estímulo, sem procurar vencer espontaneamente as dificuldades.

Compete ao mestre dar vida ao aprendizado, lançando mão de artifícios engenhosos e atraentes, que despertem o gôsto pela leitura. A escolha do método é também de muita importância.

Tenho observado que a criança encontra dificuldade em formar sentenças completas à vista de uma gravura, mas diz espontaneamente: gato, cachorro, faca, etc. 
Por esse motivo, baseei meu processo de "Alfabetização pela Imagem" no "Método Analítico-Sintético", mas partindo da palavra. Foram escolhidos vocábulos familiares e de fácil articulação.

Consiste, êsse processo, em relacionar a sílaba inicial de cada vocábulo com um "desenho chave". Quando a criança vê escrita determinada sílaba ou letra, imediatamente associa os sinais gráficos que a representam à imagem do desenho a que está ligada, acordando na ideia o som correspondente.

Cada desenho excita energicamente o interesse, é poderoso auxiliar de intuição e de análise, e oferece apôio à memória.

Assim, dentro de cada lição, o aluno pode praticar a palavração, a silabação e a soletração pois a sílaba, a letra e mesmo algumas palavras menos conhecidas deixam de ser abstrações para o espírito infantil.

A criança normal aprende por si mesma e a missão do mestre reduz-se a guiar e estimular o trabalho do aluno. A retardada necessita da assistência direta do professor. Por meu processo, até esta memoriza com relativa presteza as diferentes sílabas.

Com a leitura sistemática dos "Quadros Mnemônicos" a criança adquirirá facilidade, segurança e rapidez. Essa repetição continuada poderá afigurar-se monótona, mas posso afiançar por experiência própria que os pequeninos sentem com isso indizível prazer e entusiasmo.

A cópia diária dos "Quadros para Cópia", apesar de não apresentar atrativos para certos alunos, é imprescindível para o aprendizado simultâneo da leitura e da escrita.

Diz Aguayo em sua "Didática da Escola Nova":

Não devem ser descuidados e menos ainda suprimidos os trabalhos e exercícios que, faltos embora de interesse, são indispensáveis para adquirir facilidade e prática ou formar certos hábitos e atitudes mentais exigidos por todo o trabalho de bôa qualidade. (LIMA, 1954, p.3 apud MORTATTI, 2000, p. 208-209)

A autora justifica a escolha do método analítico-sintético, embasada em suas próprias experiências, atribuindo a imagem como elemento fundamental para aquisição da escrita e leitura. Ensinava palavras supostamente de fácil articulação e utilizadas pelo universo infantil e seu cotidiano. Contudo, Branca Alves de Lima concebia como essencial a permanência de práticas consideradas tradicionais para o êxito da alfabetização; como por exemplo, a cópia como ajudante da memorização grafêmica e sonora por meio da repetição. Quanto ao método analítico-sintético aplicado, verifica-se um resultado muito satisfatório por mais de 50 anos, conservando a sua estrutura, havendo poucas modificações decorrentes dos avanços tecnológicos e das mudanças das regras ortográficas. Além do mais, Branca Alves de Lima foi uma figura representante daquilo que se chamaria hoje "empoderamento feminino" no meio editorial e acadêmico, sendo frequentemente citada pelos intelectuais com mais de 47 artigos de 1950 a 2000, tornando-a o best-seller das cartilhas no Brasil (PERES et. al., 2016).

Assim como os demais autores, a escolha do nome, também compreende seus ideais, defendendo o ensino sem fardos, leve e vivo, ou seja, acreditava que era preciso "suavizar para nossas crianças o ensino da leitura, tornando-o vivo, prático e dinâmico" (LIMA, 1979, p.6 apud PERES, et. al., 2015, p.61). Para autora, a presença das imagens auxiliava no processo de alfabetização proporcionando que o aluno desenvolvesse habilidades de compreensão e interpretação, sem possuir confusões, como por exemplo, com as palavras lata e bola, semelhantes por ter a mesma configuração gestáltica, ou seja, uma letra alta e uma letra baixa. Assim, as figuras tinham por responsabilidade ajudar na identificação e diferenciação dos símbolos grafêmicos, além de despertar o interesse do público infantil. 
Cabe ressaltar que a estrutura da cartilha Caminho Suave possui uma padronização do layout; e, como ressalta Mortatti (2000):

A sequência das lições é invariável: gravura, com destaque para o traçado da letra em estudo; a sílaba inicial da palavra-chave representada pela gravura; sentenças com a palavra-chave estudadas até então; lista de palavras contendo, em diferentes posições, as sílabas estudadas; sílaba em destaque na lição acompanhada das cinco vogais, em ordem alfabética, com letra de imprensa e manuscrita; e finalmente, as letras iniciais dessa sílaba (MORTATTI, 2000, p.209).

Quanto aos exercícios são todos em letra de imprensa. Porém é solicitado ao estudante que responda apenas utilizando a letra cursiva, pois acreditava-se que esta modalidade de escrita desenvolvia a dedicação ao estudo, por meio do capricho com que deveria ser realizado o traçado de cada letra, com vistas a que se obtivesse uma grafia bonita que indicasse a excelência no estudo (MORTATTI, 2000).

Os enunciados são todos de ordem, objetivos e de fácil compreensão, vedando a estimulação do desenvolvimento complexo de interpretação e impede que o aluno exponha de forma ativa o seu posicionamento pessoal ou mesmo realize outras atividades que extrapolam aos papéis da Cartilha. Outro fator estrutural a ser mencionado é o destaque para as sílabas a serem trabalhadas, algo realizado pela diferenciação de cor, ou seja, usa a cor vermelha para ressaltar a sílaba "Ba" que será aprendida e pinta as sílabas restantes de preto, resultando na palavra "Barriga" (Imagem). Esta padronização cria um ritual de rotina escolar, permitindo ao estudante a conhecer a sequência dos conteúdos.

Imagem 3. Lição 1 (Caminho Suave)
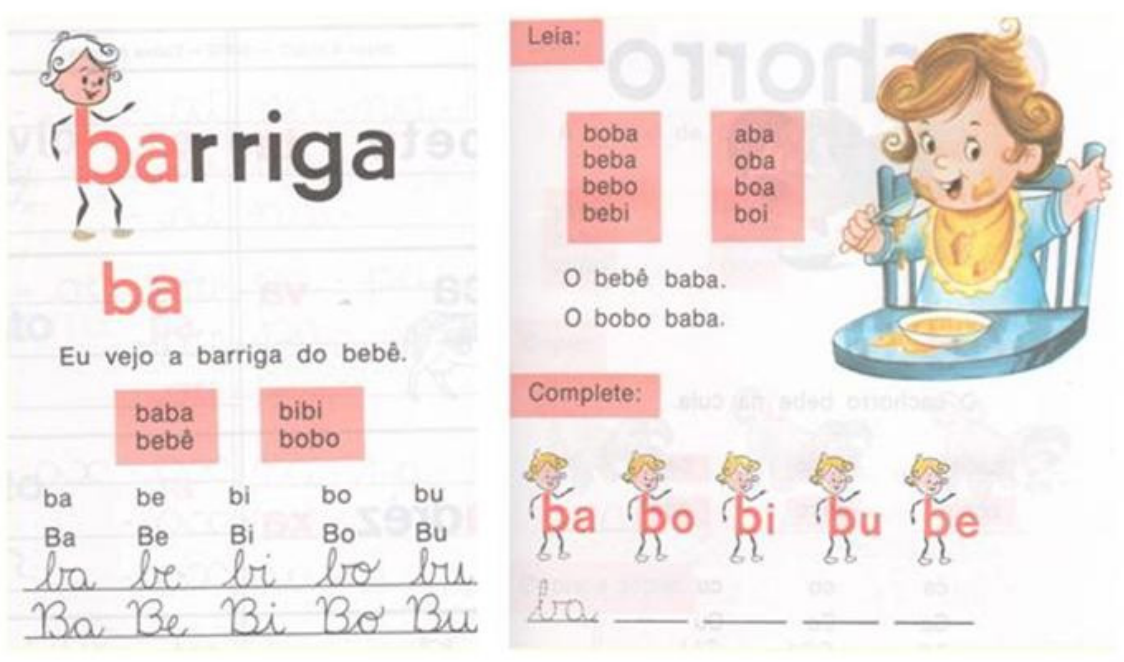

Fonte: Cartilha Caminho Suave, 1992, p.34

A lição da palavra "Barriga" é a Primeira Lição da Cartilha Caminho Suave, iniciando com a sílaba "BA". Na sequência, era apresentado o sistema alfabético brasileiro para o ensino da leitura e da escrita. Como visto na imagem, apresenta um menino magro com barriga saltada, cujo objetivo é de auxiliar na memorização através da associação da letra com a sonoridade, ou seja, "B de barriga".

Em seguida, a autora apresenta uma oração interligando a palavra chave com a figura do menino, caracterizando-o como um bebê, conforme se pode ver na tabela abaixo. Logo após, apresenta 4 palavras dissilábicas, repetindo as sílabas, todas de caráter simples e por fim apresenta a família da letra "B". 
Tabela 4. Lição 1 (Caminho Suave)

\begin{tabular}{|c|c|c|c|c|}
\hline \multirow{2}{*}{\multicolumn{2}{|c|}{$\begin{array}{l}\text { PRIMEIRA LIÇÃO } \\
\text { PALAVRA-CHAVE: barriga - ba }\end{array}$}} & \multirow{2}{*}{\multicolumn{2}{|c|}{ FAMÍLIA DO B }} & \\
\hline & & & & \\
\hline \multicolumn{5}{|c|}{ Eu vejo a barriga do bebê } \\
\hline \multicolumn{5}{|c|}{ PALAVRAS } \\
\hline Baba & Bebê & Bibi & Bobo & \\
\hline $\mathrm{Ba}$ & be & bi & bo & bu \\
\hline $\mathrm{Ba}$ & $\mathrm{Be}$ & $\mathrm{Bi}$ & Bo & $\mathrm{Bu}$ \\
\hline $\mathrm{Ba}$ & be & $\mathrm{bi}$ & bo & bu \\
\hline $\mathrm{Ba}$ & $\mathrm{Be}$ & $\mathrm{Bi}$ & Bo & $\mathrm{Bu}$ \\
\hline \multicolumn{5}{|c|}{ Cubra e copie (PALAVRAS) } \\
\hline Baba & Bebê & Bibi & Bobo & Boba \\
\hline Bebo & Bebi & Aba & Oba & Boi \\
\hline \multicolumn{5}{|l|}{ Frases } \\
\hline \multicolumn{5}{|c|}{ 1. O bebê baba. } \\
\hline \multicolumn{5}{|c|}{ 2. o bobo baba. } \\
\hline
\end{tabular}

Os exercícios são iniciados pela modalidade escrita, especificamente pelo tipo de letra cursiva, solicitando que o estudante passe por cima do traçado das palavras já apresentadas e repetindo-as mais duas vezes. O segundo exercício é para o estudante interligar as palavras iguais (semelhança visual). O terceiro exercício é de leitura, ensinando oito palavras novas, sendo todas dissilábicas, seguidas de duas frases simples utilizando como exemplo as palavras vistas. O quarto e o quinto exercício correspondem à repetição gráfica, quando se solicitava que o estudante copiasse em letra cursiva a família silábica da letra "B", consoante+vogal. O último exercício desta lição requeria que a criança copiasse e reproduzisse duas vezes as palavras vistas durante a lição.

É inegável que, por meio da cartilha Caminho Suave, Branca Alves de Lima marcou o mundo editorial, lutando e acreditando que o seu material mudaria a vida de milhares de pessoas com a leitura e escrita. Por fim, analisar as lições da cartilha Caminho Suave com o embasamento de fontes documentais, permite buscar a compreensão do que significava "suavizar" o caminho da alfabetização, tão sujeito ao sucesso ou ao fracasso.

\section{Considerações Finais}

No Brasil, desde o final do século XIX, nota-se que a escola como instituição social vem atribuindo responsabilidade pela instrução e o acesso ao mundo público à cultura letrada, oferecendo prestígio e possibilitando uma ascensão social por meio dos estudos.

É perceptível que a História da Alfabetização começa a ter mais visibilidade com a criação dos diferentes métodos, gerando um campo de disputas entre o ensino "tradicional" e o "inovador", com o objetivo de solucionar as dificuldades enfrentadas pelos estudantes no processo da aquisição da leitura e da escrita, especialmente na escola pública. Dessa maneira, cabe ressaltar, a importância encontrada na realização da pesquisa, visto que a área de alfabetização com uma abordagem histórica, enfocado nos estudos dos materiais de primeiras letras, ainda é um campo pouco explorado, tanto pelo desinteresse advindo com o movimento construtivista, quanto por serem fontes primárias consumíveis com desfecho ao descarte, dificultando o acesso. Neste sentido, fica o estímulo às pesquisas, 
a fim de iluminar o passado e atrair contribuições para o presente. Afinal, aprender a historicidade dos modos passados de ensinar a ler e escrever supõe, na outra margem, trabalhar algumas questões que, indagando o futuro, desafiam o tempo presente" (BOTO, 2011, p. 8).

Dessa maneira, estudar as três cartilhas, cada uma em seu tempo, significou compreender os impactos gerados na educação brasileira no decorrer de suas publicações até o momento do declínio, fosse por uma nova metodologia de ensino (no caso das primeiras duas cartilhas) ou pelo movimento construtivista (no caso da Caminho Suave).

Pode-se afirmar que esses materiais de ensino de primeiras letras permitem que se compreenda a cultura escolar, em sua dimensão histórica, embasando a aprendizagem passo-a-passo, formando cidadãos, de acordo, com os pensamentos éticos e morais da sociedade vigente. Sob tal aspecto, é notória a similaridade presente nas três cartilhas, nas quais se busca modificar o indivíduo pela ação educativa, atribuindo à escola uma função social e a urgência ressaltada pela rapidez em ensinar o maior número de pessoas. Democratizar o ensino é sempre algo visto como estratégia para desenvolver o país, compreendendo que a educação sempre teria estado vinculada aos aspectos econômicos.

Assim buscou-se compreender o papel desempenhado por cada cartilha, respaldando as necessidades de cada época, em um estudo contextualizado, que examina as cartilhas como textos culturais e patrimônios brasileiros: João de Deus foi um homem que marcou o Brasil com seu método inovador; Lourenço Filho foi um protagonista de incansáveis batalhas em prol da escola pública e de métodos eficazes; e Branca Alves de Lima, com a ênfase na imagem como requisito para o simbolismo da escrita, foi uma guerreira na tentativa de sanar as dificuldades de seus alunos diretos e indiretos. Pode-se, por fim, acreditar que as cartilhas, ao contrário do que se possa pensar atualmente, não são o "mal" da sociedade ou mesmo da história da educação brasileira (MORTATTI, 1999), mas um elemento que, a seu tempo, promoveu avanços e desenvolvimento pedagógico no âmbito da história da alfabetização. Merecem, pois, pelo território da investigação acadêmica, ser vistoriadas e revisitadas.

\section{Referências:}

BERTOLETTI, Estela Natalina Mantovani. Lourenço Filho e a alfabetização: um estudo de Cartilha do povo e da cartilha Upa, cavalinho. São Paulo: UNESP, 2006.

BOTO, Carlota. A civilização escolar como projeto político e pedagógico da modernidade: cultura em classes, por escrito. Cadernos CEDES 61: "Arte \& manhas dos projetos políticos e pedagógicos", CEDES/Campinas, v. 61, n.dez. 03, p. 378-397, 2003.

BOTO, Carlota. Alfabetização: entre o método fônico e o construtivismo, a necessidade de reconstruir o debate. Jornal da USP, São Paulo, 03 maio 2019. Disponível em: <https://jornal.usp.br/artigos/alfabetizacao-entre-ometodo-fonico-e-o-construtivismo-a-necessidade-de-reconstruir-o-debate/>

BOTO, Carlota. Aprender a ler entre cartilhas: civilidade, civilização e civismo pelas lentes do livro didático. Revista Educação e Pesquisa, São Paulo, v.30, n.3, p. 493-511, set./dez. 2004.

BOTO, Carlota. Ler, escrever, contar e se comportar: a escola primária como rito do século XIX português. Tese doutorado. 1ed. Portugal: Imprensa da Universidade de Coimbra, 2012.

CAPOVILLA, Alessandra G.S.; CAPOVILLA, Fernando C. Alfabetização: método fônico. São Paulo: MEMNON, 2007.

COLELLO, Silvia de Mattos Gasparian. Caminho Suave: você se lembra dela? [Depoimento a Maria Clara Vieira], 2016. 
DOCUMENTÁRIO. D-06 Reforma Sampaio Dória. UNIVESP, 2010. Disponível em:<https://www.youtube.com/ watch?v=evSz_gCOWiO>. Acesso: nov., 2019.

FRADE, Isabel Cristina Alves da Silva. Métodos de alfabetização, métodos de ensino e conteúdos da alfabetização: perspectivas históricas e desafios atuais. Santa Maria, v.32, n. 01, p.21-40, 2007. Disponível em: <http://www. ufsm.br/ce/revista>

LEMME, Paschoal. O Manifesto dos Pioneiros da Educação Nova e suas repercussões na realidade educacional brasileira. Revista Pedagógica de Estudos Pedagógicos, v. 86, n² 212, pp. 163-178, jan/ abril, 2005.

MARCILIO, Maria Luiza. História da alfabetização no Brasil. São Paulo: EDUSP, 2016.

MONARCHA, Carlos. Lourenço Filho. Recife: Fundação Joaquim Nabuco, Editora Massangana, 2010. 152 p.: il. (Coleção Educadores).

MONARCHA, Carlos; FILHO, Rui Lourenço. Por Lourenço Filho: uma biobibliografia. Coleção Lourenço Filho. Instituto Nacional de Estudos e Pesquisas Educacionais: Brasília - BR. Vol. 1, 2001.

MORTATTI, Maria do Rosário Longo (org.). Alfabetização no Brasil: uma história de sua história. São Paulo; Marília: Editora UNESP/Oficina Universitária, 2011. v. 1. 309p .

MORTATTI, Maria do Rosário Longo (org.). História dos métodos de alfabetização no Brasil. Conferência: Alfabetização e letramento em debate. Brasília, 2006.

MORTATTI, Maria do Rosário Longo. Os sentidos da alfabetização (1876-1994). São Paulo: UNESP, 2000.

PERES, Eliane; RAMIL, Chris de Azevedo. Alfabetização pela imagem: uma análise iconográfica da cartilha Caminho Suave e do material de apoio. Revista Cadernos de Pesquisa em Educação - PPGE/UFES, Vitória, ES, a. 12, v.19, n.41, p.53-79, jan/jun. 2015.

PERES, Eliane Teresinha; VAHL, Mônica Maciel; THIE, Vania Grim. Aspectos editoriais da cartilha Caminho Suave e a participação da Editora Caminho Suave Limitada em programas federais do livro didático. MaringáPR: Revista Brasileira de História da Educação, v. 16, n. 1 (40), p.335-372, jan./abr., 2016.

PERUQUE, Jéssica Toro. Cartilha Caminho Suave: História e memória dos 65 anos de publicação. TCC sob orientação Dra. Analete Regina Schelbauer. Maringá: Universidade estadual de Maringá, 2016.

RUIVO, Isabel. João de Deus: Métodos de leitura com sentido. Actas do VI Encontro Nacional (IV Internacional) de Investigação em Leitura, Literatura Infantil e Ilustração. Braga: Universidade do Minho, out. de 2006.

SOARES, Magda. Letramento e alfabetização: as muitas facetas. Minas Gerais: Revista Brasileira de Educação, $n^{\circ} 25$, p. 5 - 17, jan/fev/mar/abr. 2004.

TV ESCOLA e Fundação Joaquim Nabuco. Documentário: Lourenço Filho. Série: Educadores, 2011. Disponível em: < https://tvescola.org.br/tve/video/educadores-lourenco-filho>.

Recebido em: 01/04/2020

Aceito em: 30/06/2020 